\title{
4. The question of crime: How much does the public have the right to know?
}

\section{ABSIRACII}

The public right to know is of particular significance when considering the reporting of crime and criminal justice. The internet has demonstrated strong influences upon crime reporting in mainstream media, including the range of material it provides to audiences. In addition, the internet has exposed journalists to new legal and ethical ramifications that accompany reportage on an international scale and, while it may be 'giving the people what they want', it has also exacerbated the controversy surrounding the perennial question of how much the public has a right to know. Research suggests that giving online readers what they want in the context of crime reporting includes the transition to shorter, more concise stories at first point of access, with further background and detail available through links to multi-media facilities. Often these offer far more graphic detail and specificity than is available in mainstream media, bringing the audience closer to the scene of the crime and the people involved. This is reopening the argument of the right to know versus the desire for privacy. These developments raise questions about the level of gatekeeping that is applied to internet coverage of crime. Analysis of media reporting on the disappearance in May 2007 of British toddler Madeleine McCann has shown how online access has raised an increasing number of ethical and legal issues relevant to the question of whether giving audiences what they want can conflict with what the public have a right to know. This article examines how the internet has influenced crime reporting and gatekeeping online.

Keywords: crime reporting, criminal justice, ethics, gatekeeping, internet, online journalism, privacy

JOY CAMERON-DOW

Bond University 
$\mathrm{T}$ IHE INTERNET has many advantages over its mainstream counterparts: it offers immediacy, global coverage and accessibility, Each of these expands the parameters of knowledge available to the public, contributing incrementally to public perception of the right to know. Today, traditional and online media have contributed to 'a society in which we are inundated with so much information that it is difficult to assess what specific impacts media have on our ideas and attitudes' (Dowler, Fleming \& Muzzatti, 2006). The multitude of facts and opinions now freely available on the internet have led to a public acceptance and expectation of this overabundance of information, but these same advantages pose an equally impressive potential threat, particularly in the context of crime reporting. This article explores some of the ways in which a technology, the internet, has changed crime reporting, by examining the issues of privacy and coverage of court proceedings, citing examples relating to the cases of Scott Peterson and Madeleine McCann. The article also addresses the question of online gatekeeping.

\section{Privacy}

The profound effect of the internet on the media and the way in which news is reported is due in no small measure to the way in which the audience receive and react to information gleaned from new media. Media owner Rupert Murdoch (2005) spoke of the next generation having 'a different set of expectations about the kind of news they get...they want control over their media, instead of being controlled by it' and Keck (2002) explained that people were more inclined to 'scan' the internet than to peruse it in detail, as they would a newspaper. They also read more slowly online, a practice calling for shorter, more concise stories. Perhaps the most importance difference, according to Keck, was that the web page must offer multimedia facilities if it hoped to maintain readers' attention and keep them informed.

Yet, in the context of crime reporting, this determination to keep the public informed is dialectically at odds with the notion of privacy. When crimes are reported, particularly those of a sensational nature, the media invoke the ethic of the public right to know, sometimes ignoring the individual's desire for privacy although valid reasons can exist for invading this privacy on occasion. Hurst and White (1994, p. 169) referred to the public support resulting from publicising the plight of victims, as well as the media's contribution to 
eliciting information and tracing otherwise elusive suspects.

Nonetheless, does the public right to know, whether justified or not, extend to the most intimate details, in short the invasion of the privacy of the victim, or even the victim's or perpetrator's families? (The Smoking Gun, 1997; Cunningham, 2000; Gerstenkorn, 1999). Social networking sites carry many intimate details, but in most instances individual subscribers include these voluntarily. However, other internet reporting is frequently guilty of observing no such borders. Despite Surette's (1998) contention that certain issues 'should not be subject to publication,' a number of these elements, including 'intimate personal letters, details of home life, photographs taken in private places, photographs stolen from a person's home' frequently find their way on to the internet, adding significance to issues of privacy and confidentiality. Gunter (2003, p. 113) made the point that official records, formerly available in hard-copy format and consequently difficult to access were now freely and easily accessible on the internet. Lynch (1998), writing in the American Journalism Review, raised the argument that archives were easily accessed online and remained available indefinitely. The period that must elapse before the right to privacy takes over from the public right to know is a question of particular significance when considering crime reportage. When a criminal has paid the penalty for the crime, should the record and details remain accessible for all time? More to the point, for how long should a victim continue to be identified? Crime stories remain on the internet indefinitely on sites such as Crime Library and are there for all to see, long after the cases have been officially closed, denying those involved the privacy they often desire.

While the Code of Ethics of the Media, Entertainment and Arts Alliance includes respect for privacy (Pearson, 2004) 'there is no constitutional right to privacy in Australia, but there are some pieces of legislation which afford certain but incomplete protections' (Parliament of Australia, 2003). Paul Chadwick, former Victorian Privacy Commissioner, citing independence as 'one of the characteristics by which journalists tend to define themselves', justified his belief that privacy and journalism were compatible by quoting US First Amendment theorist Thomas Emerson:

A system of privacy is vital to the working of the democratic process. Democracy assumes that the individual citizen will actively and independently participate in making decisions and in operating the institutions of the society. An individual is capable of such a role only 
if he [or she] can at some point separate himself [or herself] from the pressures and conformities of collective life. (Chadwick, 2003)

Richards, however, expressed a more pessimistic view in his 2003 Hawke Research Institute lecture. Remarking on the journalists' fear of external regulation, he pointed out that journalists are not required to acquire a 'systematic body of knowledge' in order to practise their profession (Richards \& Sarre, 2003) and reminded his audience that journalists are more in the business of revealing information than protecting it. He argued that underlying all questions about how much and what information to reveal is the issue: 'What is the right way for journalists to deal with concern for privacy?' (Richards \& Sarre, 2003). In his 2005 book on journalists' ethics, Richards further noted how 'the forces of corporatism' are threatening professional standards, 'encouraging individual journalists to put profits ahead of ethics...' In the process, media corporations, he noted, are quite prepared to use the rhetoric of press freedom and the Fourth Estate as a bulwark against attempts at regulation, even when those attempts are 'grounded in notions of accountability'. (Richards, 2005, p. 91). These concerns apply clearly to crime reporting and the treatment of victims of crime and alleged perpetrators.

The influence of media proprietors in resisting privacy regulation was also addressed in the 2003 Hawke Research Institute Public Lecture series by Rick Sarre who referred to the limited range of privacy 'rights' in the Australian Constitution compared with those in other countries.

\begin{abstract}
Australian governments have consistently been reluctant to enact protection of privacy laws specifically, probably because of the dilemmas facing law reformers in convincing media proprietors that such initiative would have no effect upon legitimate journalistic endeavours. (Richards \& Sarre, 2003, Common Law \& Legislation, para. 3)
\end{abstract}

The public's right to know and the individual's desire for privacy remain apparently irreconcilable differences in media terms and are likely to become even more of a debatable issue with reporting on the internet. What newspapers can publish is determined largely by the amount of space available; no such restrictions apply to the internet: more copy can be added at will and every detail can be included (South, 2000). As details increase, so privacy decreases. Many newspapers now publish on the Internet their databases of 
crimes reported to police in their areas. These details are available to anyone who chooses to browse the relevant web pages.

Relating the issue of privacy to the reporting of crime and criminal justice,Surette(1998, p. 92) cited the Supreme Court argument that 'a balance between the gathering and dissemination of information and the preservation of privacy and chances for rehabilitation is a valid goal...' Yet how achievable is this goal when a trial is televised, or the most intimate information about suspects and witnesses is revealed in a gossip magazine or on a celebrity website? Even more unjustified is the intrusion into the privacy of victims. Grabosky and Wilson (1989, p. 133) noted '...the press sometimes thrive on the discomfort and pain experienced by victims and their relatives... They concede that in order to obtain a story, they engage in deception'. This was demonstrated in coverage of stories as distant as the disappearance of Azaria Chamberlain in Australia in 1980 and the more recent disappearance of Madeleine McCann in Portugal in May 2007. In the latter instance, not only were the suffering and pain of Madeleine's parents shown graphically in traditional and online media, but Daily Mirror editor Roy Greenslade wrote that the 'wild claims' about the parents were 'a sustained campaign of vitriol against a grief-stricken family' (Griffiths, 2008). Additionally, alleged suspect Robert Murat took legal action against three Portuguese newspapers for defamation and invasion of privacy (Reis, 2008) and was paid $£ 600,000$ in libel damages by four UK newspaper groups, 'who acknowledged making "false claims"' (Luft \& Plunkett, 2008). While some of the media attention might well have been attributed to an attempt to publicise the disappearance of the toddler, Grabosky and Wilson $(1989$, p. 133) refuted the reasoning that might justify this notion: 'the emotional prose which arouses passion, anger and calls for draconian penalties often negates the advantages of a higher profile for victims and their plight.'

Paparazzi today have no compunction about revealing private details of their subjects and, in many instances, convicted criminals who have served their sentences are subject to a level of exposure in the media that puts their safety in jeopardy. Sub judice laws limit the exposure of details relating to those who have been charged and whose cases are under review, but respect for privacy of the individual appears to be becoming less and less of a concern to the media, both traditional and online, with privacy on the Internet remaining much less easy to regulate and control. Court proceedings particularly are affected by increasing public exposure on television and the internet. This was 
demonstrated in the 1995 retrial of the Menendez Brothers for the murder of their parents, when Judge Stanley M. Weisburg of Los Angeles County Superior Court banned cameras from the courtroom, saying: 'The court concludes that the enduring intensity of interest in this case immeasurably increases the likelihood that jurors will be exposed to potentially prejudicial electronic media coverage about this case outside the courtroom' (Noble, 1995). Similarly, the internet coverage was blamed for prejudicing Bradley John Murdoch's chances of obtaining a fair trial (Meyerhoff, 2004).

\section{Coverage of court proceedings}

For instance, does the public right to know and the importance of transparency extend to the complete coverage of murder trials, 'most intrusive of news media access to the judicial system'? (Surette, 1998, p. 95) Presently, live television coverage is not permitted in every courtroom in the United States; it was banned in 1937 and the ban overturned in 1953 in Oklahoma City. When Scott Peterson was tried for the 2002 murder of his wife, the judge not only moved the trial from Modesto, California to Redwood City, but also banned video cameras in the courtroom for the verdict. Nonetheless, one station aired a live audio stream of the reading of the verdict. In Australia, the Federal Court was the first Australian superior court to allow: '...the recording of judgments for subsequent broadcast; the videotaping of a whole trial (Yorta Yorta) for potential televising; and the live broadcast of a judgment (MUA/Patricks Full Court)' (Phillips, 1998). In New Zealand, the In-Court Media Coverage Guidelines 2003 laid down standard conditions for television coverage in the courtroom and stipulated that such coverage should not include filming of jurors or members of the public attending the trial (New Zealand Ministry of Justice, 2003). Also, 'Film taken must not be broadcast on television until at least 10 minutes have elapsed.' In 2005, Justice Keith, a judge of the Supreme Court of New Zealand, stated in a paper delivered in Washington '...court proceedings in New Zealand, including jury trials, are televised if the trial judge ... so decides' (cited by The Honourable Justice John Basten, 2005).

The internet has supplemented its broadcasts with creative use of interactivity, as evidenced in the O.J. Simpson trial, '...the first to be fully discussed and diagnosed on the internet', (Greek, 1996). People who followed the trial did so with the aid of every online facility available: email, chat rooms, news groups and web pages. Court TV broadcast the entire trial online and created 
an O.J. web site; thousands of ordinary people created their own web sites, where the case and subsequent verdict were discussed openly, with information traded at will. This interactivity continues, long after the civil trial produced a guilty verdict and O.J. Simpson himself moved to Florida. Since then, he has become involved in further criminal proceedings, again covered extensively on the internet.

The impact of this extensive coverage cannot be over-emphasised. Surette (1999) referred to the 'news media echo effect' whereby high-profile media trials influenced other, less publicised proceedings, an effect that can only be exacerbated by additional internet attention. Thus online coverage has the capacity to increase public knowledge dramatically. The public already often has access to a suspect's capture and arrest through both television and the internet. As the internet dramatically increases the number of observers who can publish material, could live reporting of police interviews or observations of those in captivity soon be transmitted via internet social media such as twitter or blogs? In addition, the public has already been visually transported to crime scenes and seen and heard jurors discussing their verdicts after the trial, as happened with coverage of the Scott Peterson case in USA Today (Ritter, 2004). Scott Peterson was tried in California for the murder of his wife and unborn son. During the course of the trial, the judge removed one of the jurors (Hilden, 2004), while four other members of the jury subsequently spoke to MSNBC journalist Rita Cosby about the trial, a book they had written and the verdict (Cosby, 2007). Could the camera eventually intrude inside the jury room itself, to witness consideration of that verdict? Will crime reconstruction and simulation become even more graphic and specific? As far-fetched and unwelcome as some of these ideas might seem, it bodes well to remember that multimedia capacities of the internet itself were just as far-fetched before their inception.

As a reporting medium, the internet can be used to spread information quickly and effectively and to cast a wide net for leads (Surette, 1998, p. 232). The London bombings on 7 July 2005 are a case in point. Four male suicide bombers killed 52 people and themselves when they detonated explosives on three underground trains and a bus in Central London. 'In 56 minutes', an Associated Press (AP) reporter observed on July 7, 'a city fresh from a night of Olympic celebrations was enveloped in eerie, blood-soaked quiet' (Allan, 2006 , p. 144). The BBC was in the forefront of news organisations reporting the event on the internet and online newspapers followed. The public 
were quick to submit their own first-hand accounts, sending a plethora of visuals, text messages, videos and emails. Allan was unequivocal in attributing responsibility for the news dissemination: 'This remarkable source of reportage, where ordinary citizens were able to bear witness, was made possible by the internet' (2006, p.152).

In addition, a reporter today can send a story from anywhere in the world back to the point of publication in seconds or, in many instances, can post that story directly on a news site. In the context of reporting crime and the criminal justice system, while superficially giving the audience 'what it wants', the dramatic speed of publication raises questions about whether the accelerated speed of the news production process has over-ridden gatekeeping on the internet, a point of view investigated next.

\section{Gatekeeping}

McQuail (2000, p. 276) defined gatekeeping as 'the process by which selections are made in media work, especially decisions whether or not to admit a particular news report to pass through the 'gates' of a news medium into the news channels' (White, 1950; Shoemaker, 1991, cited in McQuail, 2000). These selections are made at different levels of the reporting hierarchy, taking into account 'When knowledge moves, it is always through a process of constructive interpretation' (Ericson, Baranek, \& Chan, 1991, p. 356). Surette pinpointed 'checkpoints' in the news production cycle, 'where individuals select, mold, and pass on crime news candidates', (1998, p. 63) and where the story is filtered through nine points in a selection process, beginning with the perpetration of the crime, moving to its recognition and reporting by the victim, thus becoming a crime known to the police, subsequently passing on from the police public information officer to the crime reporter before finding its way to the crime news pool, to be edited by the news producer or editor, then printed or broadcast as crime news, finally reaching the audience as 'news of crime in society'. The cycle is a linear one, subject at each stage to subjective selection filtering before onward transmission, with a potential diminution in objectivity, fairness and accuracy along the way.

White (1950, cited in Singer, 1998) ascribed the gatekeeping principle to journalists, when examining the news items selected by a wire service editor of a small newspaper. Stories were selected on the basis that 'the community shall hear as a fact only those events which the newsman, as the representative of his cultures believes to be true'. As this representative, the 
journalist was acting as his own 'self-proclaimed' gatekeeper (Deuze, 2007), a situation Singer claimed had changed radically with the advent of the worldwide capacity of the web. 'It would seem that the notion of gatekeeping goes right out the window with the internet' (Singer, 1998). This was endorsed by BBC director of global news Richard Sambrook (cited in Allan, 2006, p. 169), when he spoke of news organisations no longer owning the news and attributed this to the influence of the internet: 'Thanks to the internet, the role of media gatekeeper has gone. Information has broken free and top down control is slipping inexorably away.' However, Singer countered his claim with the suggestion '...that online users...may actually be looking for some sort of gatekeeper'. Interviewed for a recent study relating to the internet and the reporting of crime and media, Kim Jordan (ABC) agreed: 'I personally have a view that citizen journalism was a nice concept, but the citizens themselves are too busy to read all the crap that's out there and they actually need gatekeepers to whack it into some sort of shape. They'd be journalists' (Jordan, 2008, cited in Cameron-Dow, 2009).

However, an important factor to be considered in each case is the grey area, that zone between deliberate and subconscious or routine gatekeeping, particularly in mainstream publications. Cassidy's (2006) study on gatekeeping stated: 'Routine level gatekeeping forces in this study were found to exert more influence than individual gatekeeping forces on the professional role conceptions of print and online newspaper journalists' (p. 17). Online publications seek interaction from their audiences, but frequently have difficulty dealing with the unrestricted access it offers. Chung (cited in Deuze, Bruns, \& Neuberger, 2007) referred to the same conflict when she wrote: '...initiatives to implement interactive features are increasing - but journalists find it difficult to navigate the challenges this brings to established notions of professional identity and gatekeeping.'

Interviewed for the study referred to previously, relatingt o the internet and the reporting of crime and criminal justice, senior reporter Neil Mercer (Sunday Telegraph) explained:

We are seeking to get readers' comments...we're looking for people to get on our site and interact with us...one of the problems is people can say whatever they like and a lot of the time it's not screened... that's a problem for newspapers down the track. (Mercer, 2008, cited in Cameron-Dow, 2009) 
Yet, even in this seemingly unrestricted area, an element of gatekeeping is both desirable and possible. A broadcast and online news editor of a major Australian news outlet said control was exercised 'in a minor way'.

We invite, on certain parts of our website, people to contribute and those contributions are 'gatewayed'. Not here, not here. I mean our state-based pages are purely news. We're not inviting people to blog. I must say the blogosphere is like space filled with space junk at the moment. (Jordan, 2008, cited in Cameron-Dow, 2009)

Some new online sites are exercising gatekeeping by inviting readers' comments on selected articles only. The crime reporting aspect of this was exemplified on news.com.au on September 19, 2008. Included in news coverage that day were articles on the Wall Street stock market surge, compensation awarded to Australian paedophile Dennis Ferguson, attempted child abductions and a double shooting. While public comment was invited on the Wall Street story, it was not sought with the crime articles. Moreover, even permitted comments were not immediately posted on the webpage. Contributors were asked to divulge their name, email address and telephone number, with the proviso that they 'would be contacted' if their comment was to be posted. Publication guidelines listed terms and conditions that included the collection of personal details about the sender. This practice showed both selectivity and potential editing, two more forms of gatekeeping which, in this instance, applied particularly to crime reporting.

Stacey Hunt wrote in the New Zealand Herald (online) that the internet had 'blurred the lines of news and hearsay and the result is trial by global gossip' (Hunt 2007), while Mills (2007), writing in the Sunday Times, pointed out 'there are no limits at all' and equated the 'electronic free-for-all...in particular, the blogosphere' with the much earlier custom of throwing 'rotten eggs and squashed tomatoes' at suspected criminals. She quoted a report calling the internet a 'Wild West of crime' and maintained that, while television and print media had been reasonably restrained in their coverage, online contributors had observed no such boundaries. This suggests the issue of online gatekeeping has particular relevance in internet reporting of high-profile criminal case, although it must be acknowledged that some of these problems have not previously existed in crime reporting by the tabloid press.

Yet it was online that the disappearance of Madeleine McCann highlighted the importance of retaining the gatekeeping principle. As mainstream

80 PACIFIC JOURNALISM REVIEW 15 (2) 2009 
and online media received unprecedented public comment, the tide of public opinion turned vociferously against the McCanns and the 'hate campaign on the internet' (Gill, 2007) compelled the editor of their local newspaper, the Leicester Mercury, to close the online discussion forum altogether, shutting the gate completely and barring the public from further interactivity.

\section{Conclusion}

In the area of crime reporting, the issue of the relevance and application the public right to know principle is increasingly contentious. The internet has removed logistical constraints imposed by different sectors of mainstream reporting, whereby certain graphic or audio details are excluded. No such exclusions apply online, where even old and outdated records can be resurrected at will. The notion of privacy is seldom a consideration and the process of retraction or apology, a part of mainstream practice, is rarely followed on the internet (Lynch, 1998). Misinformation remains in place, with sometimes lasting damage to someone accused unjustly of a crime or even inadvertently named as a victim.

That same misinformation would play a meaningful part in determining the reader's understanding and analysis of a story, especially a crime report. This was the case with the McCanns, where unsubstantiated comments created a self-generating onslaught of rumours and accusations (Wetsch, 1995-2006). When it was officially announced the McCanns were no longer suspects in the case, it was difficult to find a single online apology or retraction. In that instance, the public right to know was not extended to the public right to know the truth, an online equivalent of the earlier traditional press treatment in 1980 of Lindy Chamberlain in Australia.

However, it can be argued that the public right to know can be given too broad an interpretation when considering coverage of court and jury proceedings. Apart from the potential repercussions of the news media echo effect described above (Surette, 1999), extensive online coverage has the potential to influence jurors' deliberations, while post-trial interviews could jeopardise their safety. Although cameras in the courtroom remain a judicial decision in most countries, some form of regulation would seem to be indicated to prevent a recurrence of the public frenzy that surrounded the Scott Peterson and O.J. Simpson trials, details of which remain accessible.

Similarly, the multitude of crime-related websites continues to reflect graphic information, accurate or otherwise, about perpetrators, their victims 


\section{PUBLIC RIGHT TO KNOW}

and crimes. With the media synergy between mainstream and online reporting, these details - again accurate or otherwise — will inevitably find their way to mainstream publications, despite gatekeeping efforts. The interactive properties of the internet hold potential for extreme editorial action at either end of the spectrum. Online publications depend to a great extent on contributions from the public, yet it is impossible to predict the direction and expression of that public opinion. Where the site is open and not described as an authoritative source, or even where controversy or sensationalism is welcomed, an editor or publisher might opt in favour of unrestricted interactivity. However, as has been identified in this paper, online editions of mainstream publications as well as legitimate online news sites are already choosing to institute gatekeeping practices of their own. So the decision is more a case of ' $w$ hat the public has the right to know,' than 'how much the public has the right to know,' a distinction that will entail editorial involvement, just as it does in mainstream media. The internet has given the public the right and the ability to 'frame' its own stories and know as much or as little about each as it chooses.

\section{References}

Madeleine McCann. (2008). Retrieved on 29 September, 2008, from www.news.com. au/feature/ranked/0,,5013933,00.html

Allan, S. (2006). Online news: Journalism and the internet. Maidenhead: Open University Press.

Basten, T. H. J. J. (2005). Court and media relationships. Paper presented at the National Judicial College, Beijing, Conference, Beijing.

Cameron-Dow, J. (2009). Spinning the web: The influence of the internet on the reporting of crime and criminal justice in the traditional media. PhD epublications@ bond Gold Coast: Faculty of Humanities and Social Sciences, Bond University.

Cassidy, W. P. (2006). Gatekeeping similar for online, print journalists. Newspaper Research Journal, 27(2), 6-23.

Chadwick, P. (2003, March 28). Uses of transparency: Journalism and privacy.

Paper presented at the 2003 Privacy Issues Forum, Wellington.

Cunningham, B. (2000). Covering crime the internet way. Journal, (March/April). Retrieved on 6 November 2006, from www.findarticles.com/p/articles/mi_ga3613/ is_200003/ai_n8887319/print

Deuze, M. (2007). Journalism in liquid modern times. Journalism Studies, 8(4), 671-679.

Deuze, M., Bruns, A., \& Neuberger, C. (2007). Preparing for an age of participatory news. Journalism Practice, 1(3), 322-338.

Dowler, K., Fleming, T., \& Muzzatti, S. L. (2006). Constructing crime: Media, crime and popular culture. Canadian Journal of Criminology and Criminal Justice, 48(6), 837-850. 
Ericson, R. V., Baranek, P. M., \& Chan, J. B. L. (1991). Representing order: Crime, law, and justice in the news media. Ballmoor, Buckingham: Open University Press.

Gerstenkorn, R. (1999, October 27). The mystery of JonBenet Ramsey. Retrieved November 6, 2006, from www.geocities.com/Area51/nebula/9337/jonbenet. html

Gill, C. (2007, July 26). McCanns victims of web hate campaign. Daily Mail. Retrieved on 25 September 2007, from http://explore.dailymail.co.uk/people/ mccann madeleine

Grabosky, $\overline{\mathrm{P}}$., \& Wilson, P. (1989). Journalism and justice: How crime is reported. Leichhardt: Pluto Press Australia Ltd.

Greek, C. (1996). OJ and the internet: The first cybertrial. On Crime and Media?

Florida: Florida State University. Retrieved on 4 October 2003, from www.criminology.fsu.edu/crimemedia/lecture11.html

Griffiths, P. (2008). Madeleine McCann's parents win damages and apology. news. com.au

Gunter, B. (2003). News and the net. Mahwah, NJ: Lawrence Eribaum Associates Inc. Publishers.

Hilden, J. (2004). The dismissed juror in the Peterson case: Why he should have been kept on the jury. [FindLaw]. Retrieved on 29 July 2009, from julhil@aol.com

Hunt, S. (2007, September 17). UK media raise doubts about McCann police. The New Zealand Herald, pp. A1-2

Hurst, J., \& White, S. A. (1994). Ethics and the Australian news media. South Yarra: Macmillan Education.

Keck, E. (2002). The changing language of the metaphor. Austin: University of Texas.

Luft, O., \& Plunkett, J. (2008). Madeleine McCann: Newspapers pay out $£ 600,000$ to Robert Murat [Electronic Version]. Retrieved on 21 October 2008, from guardian.co.uk

Lynch, D. (1998). Without a rulebook: Cyberspace presents journalists with an entirely new set of ethical dilemmas. American Journalism Review, 20(1), 40-46.

Maybridge, M.B. (1990-2009). Biography for Rebecca Shaeffer. Retrieved on 29 September 2006, from www.imdb.com/name/nm0769726/bio

McQuail, D. (2000). Mass communication theory (4th ed.). London: Sage Publications.

Meyerhoff, G. (2004). Innocent until proven guilty? Not in Australia's outback! Retrieved 28 January 2008, from http://garywmeyerhoff.blogspot. com/2004 05 01)

Mills, E. (2007, December 8). World web of malice. Sunday Times, p.1. Retrieved on 25 September 2007, from www.timesonline.co.uk/tol/comment/columnists/ guest_contributors/article2240412.ece

Murdoch, R. (2005). Speech given at the American Society of Newspaper Editors.

New Zealand Ministry of Justice. (2003). The in-court media coverage guidelines 2003. Retrieved on 29 July 2009, from www.justice.govt.nz/media/guidelines. htm 


\section{PUBLIC RIGHT TO KNOW}

Noble, K. B. (1995, October 8). Why judge might have banned cameras from prominent trial. Journal. Retrieved on 28 January 2008, from www.nytimes.com/1995/10/08/ us/why-judge-might-have-banned-cameras-from-prominent-trial.html

Parliament of Australia. (2005). Do Australians have a legal right to privacy? Retrieved on 31 July 2009, from www.aph.gov.au/library/pubs/RN/200405/05rn37.pdf.

Pearson, M. (2004). The journalist guide to media law. Crows Nest: Allen and Unwin.

Phillips, B. (1998). Federal Court releases 'TV in courts' report. Retrieved on 1 October 2008, from www.fedcourt.gov.au/aboutct/media04.html

Reis, P. (2008). Murat takes to court three Portuguese newspapers and two TV Channels. Madeleine McCann disappearance. Retrieved on 25 September 2007, from http://gazetadigitalmadeleinecase.blogspot.com/2008/07/murat-takes-tocourtthree-portuguese.html

Richards, D. I., \& Sarre, R. (2003). 'Trust me, I'm a journalist': Journalism and ethics. Paper presented at Weaving the Social Fabric, City West, Adelaide.

Richards, D.I. (2005) Quagmires and quandaries: Exploring journalism ethics. Adelaide: UNSW Press

Ritter, J. (2004). Peterson jurors explain their decision for death. Retrieved on 1 October 2008, from www.usatoday.com/news/nation/2004-12-13-peterson_x. htm

Singer, J. B. (1998). Online journalists: Foundations for research into their changing roles. Retrieved on 15 September 2004, from www.ascusc.org/jcmc/vol4/ issue $1 /$ singer $2 . h t m l$

South, J. (2000). No secrets. American Journalism Review, 22(3), 50-55.

Surette, R. (1998). Media, crime and criminal justice: Images and realities (2nd ed.). Belmont: Wadsworth Publishing Company.

Surette, R. (1999). Media echoes: systemic effects of news coverage. Justice Quarterly, 16(3), 610-631.

The Smoking Gun. (1997). JonBenet Ramsey autopsy report. Retrieved on 6 November 2006, from www.thesmokinggun.com/archive/jonbenet1.html

Wetsch, E. (1995-2006). Serial killers true crime library. Retrieved on 1 October 2008, from www.crimezzz.net

Dr Joy Cameron-Dow is a senior teaching fellow at Bond University. This article draws upon work from her PhD thesis. An earlier version of the paper was presented at the Public Right to Know Conference: 'Giving The People What They Want', in Sydney, 17-18 October 2008. jocamero@bond.edu.au 